\title{
Un Proyecto a/r/tográfico para desarrollar investigación y práctica artísticas partiendo del texto-imagen
}

\section{A/r/tographic Project to develop artistic research and practice from the lyrics-image}

\author{
Javier Domínguez Muñino \\ Universidad de León \\ León (España) \\ javierdzm@gmail.com
}

\author{
Recibido: 03/05/2020 Revisado: 03/01/2021 \\ Aceptado: 03/01/2021 Publicado: 14/01/2021
}

\section{Resumen:}

Desarrollamos concretamente los marcos, teórico y metodológico, que sustentan la práctica educativa en Artes Visuales mediante Proyectos integrales que emplean imagen, texto y toda aquella documentación que despierte interés más allá de una obra gráfica. De este modo, el método de los cruzamientos amplía (no instruye) el horizonte que cada artista o investigador ponga a su trabajo. Tanto en los modelos transestético como holístico, reconocemos una línea joven de investigación que, nacida en Vancouver, va creando escuela conforme progresan sus prácticas experienciales. Aquí centramos la propuesta en los metalenguajes, que reaccionan críticos al logocentrismo tradicional, y permiten construir ideas propias partiendo de producciones también ajenas en lo que ya se ha descrito como 'indagación vital'.

\section{Sugerencias para citar este artículo:}

Domínguez Muñino, Javier (2021). Un Proyecto a/r/tográfico para desarrollar investigación y práctica artísticas partiendo del texto-imagen. Tercio Creciente 19, (pp. 151-167), https://dx.doi.org/10.17561/rtc.19.5487

DOMÍNGUEZ MUÑINO, JAVIER. Un Proyecto a/r/tográfico para desarrollar investigación y práctica artísticas partiendo del texto-imagen. Tercio Creciente, enero 2021, pp. 151-167, https://dx.doi.org/10.17561/rtc.19.5487 
DOI: https://dx.doi.org/10.17561/rtc.19.5487 Investigación
Artes y Gestión Cultural ISSN: 2340-9096
La cuestión imaginativa: del dibujo y la fotografía a la imagen en movimento Enero 2021

\section{Abstract:}

We specifically develop the theoretical and methodological frameworks that support the educational practice in Visual Arts. What we do through integral Projects that use image, text and all the interesting documentation; not just the graphic work. Thus, the method of data crossings widens (doesn't instruct) the horizon that each artist or researcher determines their work. Holistic models and Transaesthetics are related to a young research line of research born in Vancouver; what school are creating as their experiential practices progress. We focus our proposal on metalenguajes from a critique to logocentrism. Such metalanguages allow us to build our own ideas from productions that are also foreign; addressing an authentic vital inquiry.

\section{Palabras Clave/Key words}

Educación Artística; Transestética; A/r/tografía; Proyecto; Texto-Imagen; Objeto Estético Art Education; Transaesthetics; A/r/tography; Project; Lyrics-Image; Aesthetic Object

Sugerencias para citar este artículo:

Domínguez Muñino, Javier (2021). Un Proyecto a/r/tográfico para desarrollar investigación y práctica artísticas partiendo del texto-imagen. Tercio Creciente 19, (pp. 151-167), https://dx.doi.org/10.17561/rtc.19.5487

DOMÍNGUEZ MUÑINO, JAVIER. Un Proyecto a/r/tográfico para desarrollar investigación y práctica artísticas partiendo del texto-imagen. Tercio Creciente, enero 2021, pp. 151-167, https://dx.doi.org/10.17561/rtc.19.5487 


\section{Introducción: antecedente y justificación donde situarnos}

En anterior contribución se ha expuesto una motivación pedagógica del hecho artístico suprarrealista (o surrealista, como al fin se impuso en el traslado del francés) por tres razones fundamentales. La primera es que este hecho nos sitúa al fin de la imagensimulacro, cuando ésta ya no alberga como continente sino, todo lo contrario, se emancipa ontológicamente como un espacio-objeto propio. La segunda es que, en consecuencia (al ocaso del régimen ocular o arte retiniano -que diría Duchamp-), muere así el espectador pasivo cuando se desarrolla una mirada activa e implicada. $Y$, en tercer lugar, resultas de lo anterior, que el estudiante entra en un distinto juego relacional; dejándose alterar de un nuevo modo responsable, y concernido por el fenómeno artístico que le aborda (y al que ya no sólo el estudiante aborda de manera predispuesta y controlada).

Estas premisas han permitido razonar una recuperación parcial, o nueva lectura, de aquella Vanguardia; con encaje en el modelo curricular postmoderno (Domínguez, 2020) y, añadimos, en la metodología a/r/tográfica que triangula Investigación basada en Artes Visuales y Educación -cuestión que en este trabajo desarrollamos para tejer una descripción concreta de cómo enfocar los Proyectos-.

El precedente surrealista, clave y punto de inflexión como el dadaísta en la consideración del hecho artístico, alimenta un marco de 'epistemología visual' en que alumnas y alumnos son, ahora, agentes decisorios (porque deciden acerca de 'lo visual', que no 'visible'). Esto otorga a nuestros estudiantes universitarios la capacidad de madurar un discurso estético y crítico, imbuido de aspectos bien relacionados con el conocimiento (episteme) y con la política y ética (ethos). De ahí que hayamos hablado de un nuevo "juego" y "mirada" afectados, por la responsabilidad, y el compromiso hacia el hecho que nos aborda y concierne; que nos suscita e interpela; nos pregunta sin, previo, darnos la instrucción o respuesta.

En este abordaje el modelo de Proyecto integral, que aquí describiremos, se perfila como el más idóneo y provechoso para asumir una metodología a/r/tográfica en el aula (y fuera de ella); siendo eje de una propuesta que requiere fundamentos y detalles. Así como, también, el paradigma relacional transestético, al que dedicamos su oportuno espacio, se perfila un adecuado marco para la propuesta. 


\section{El nuevo juego de la mirada concernida y responsable}

De las Vanguardias surrealista y Dadá se aprende, no sólo en el plano general sino en el terreno educativo particularmente, el poder de la ambigüedad. Para el estudiante, el arte ha dejado de ser un conjunto de 'obras hechas' (terminadas, luego en cierto sentido muertas y sin réplica) para descubrir en él un proceso o actividad humana enormemente plural: de ahí que precisemos metodologías multimodales, visiones y actitudes holísticas, y estrategias de enseñanza-aprendizaje integrales como bien se cumplen en el método de la A/r/tografía.

Pero también se aprende el poder y la pertinencia de trabajar con el binomio `textoimagen' (a su vez estrechamente emparentado con la citada metodología). Porque en la práctica artística habremos de involucrar, necesariamente, los lenguajes y las formas del pensamiento investigador (o comúnmente llamado en la literatura 'indagador'), del pensamiento creativo, y del comentario que se guía a la par que guía la acción expresiva. Se requiere el rasgo multimodal porque estos tipos concurren en paralelo en la misma práctica, e integran un mismo acto que en la última década al fin empezamos a comprender así.

El beneficio de haber otorgado, al artista, un rol multidisciplinar que jugar 0 desempeñar, contrasta con aspectos desechables como aquel elitismo vanguardista que (leído en su contexto histórico de fuerte Positivismo) compitió abiertamente con las ciencias cuantitativas (exactas, físicas y naturales). Lo que ya ha quedado copiosamente documentado (Perelló, 2005; Emmer, 2005; Castro y Marcos, 2010; Caeiro y Muñiz, 2019). Y ese rol híbrido que desde entonces vino otorgándose al artista, no sólo alteró el hecho estético, sino que también modificó la consideración del sujeto (personas que encarnan procesos intelectuales de muy amplio espectro). De ahí que investigar, hacer y comentar sean tres verbos conjugables al unísono en la actividad artística; y de ahí también que este rol aumente el factor responsable y exija replantear la noción de mirada.

Antes de asumir el enorme paso de, un espacio representacional (simulacro o ilusión óptica), a otro espacio objetual y, más allá, conceptual (el de la idea), merecen matizarse algunas cuestiones. En una primera fase, bien podríamos identificar a los estudiantes el abandono del ocularcentrismo perceptivo: para comprender, a partir de ahí, la vía introspectiva, aun inconsciente, que siendo todavía icónica invierte el sentido de la mirada al plasmar un espacio psicológico: luego distorsionado. Donald Kuspit lo señala en El fin del arte:

"La tensión entre la anormal concepción inconsciente y la normal percepción consciente es evidente en el postimpresionismo, especialmente en Van Gogh y Gauguin, pero también en Degas y Cézanne. Continuaban pintando la realidad exterior, pero cambiaban su apariencia según los dictados de su inconsciente anormalizados, distorsionándola en efecto" (Kuspit, 2006: 87).

En una segunda fase, aquellas distorsiones (bien reflejadas en el Expresionismo) habrían de evolucionar hacia el giro capital del objeto conceptual e incluso fetiche, que ya no es imagen especular de nada sino la propia narrativa sólo allí encontrada. La 
autorreferencialidad del arte quedaba así consumada. Porque ya no se trata de emplear el arte para traducir un hecho, sino de la entera invención del hecho inaugurado en objeto artístico. Lo que, en El arco y la lira, refiriendo la creación escritural, podemos leer sintetizado con acierto: "no es una experiencia que luego traducen las palabras, sino que las palabras mismas constituyen el núcleo de la experiencia. La experiencia se da como un nombrar aquello que, hasta no ser nombrado, carece propiamente de existencia" (Paz, 2006: 157). $Y$ en este radical proceso, podemos identificar a los estudiantes el abandono del logocentrismo excluyente. Un logocentrismo, influido por Wittgenstein o Barthes, que tradicionalmente se ha asimilado al "verbocentrismo" otorgando al discurso escrito prevalencia sobre el lenguaje plástico-visual (Roldán y Marín, 2012: 38). Lo que, corregido por otro de tipo inclusivo, permite ejercer el binomio 'texto-imagen' sin jerarquías que alienen o quiebren la plural unidad del proceso.

Ya desembarazado de los imperativos del ojo y del verbo, el estudiante puede manejarse más allá de aquel reducto retiniano y monolingüístico. En este salto o enorme paso dado, algo ha debido ocurrir con la mirada que ahora enfrenta objetos y acciones caracterizados por la ambigüedad y el metalenguaje.

La mirada supone también un proceso fásico que sólo puede comprenderse bien en paralelo al del 'hecho artístico' ('imagen', 'objeto' o 'idea'). En el análisis de Aumont (1992) se describe un esquema elemental que ya en la concepción implica ciertas fisuras: de lo orgánico-sensorial (lo visible) a lo mental (lo visual), y de allí a lo definitivamente imaginario, intencional o hermenéutico con que nos convertimos en fabricantes de nuevos sentidos y de discursos. Interpretamos y creamos como actos emancipatorios. Pero cabría comentar tres elementos esenciales atribuidos a la mirada. $\left.1^{\circ}\right)$ La del sujeto o cuerpo fenoménico que describe Merleau-Ponty (2010) con la doble dimensión de quien, por una parte, pertenece al mundo $\mathrm{y}$, por otra parte, lo dota de sentido otorgándole un nuevo significado o correlato. Lo que el influyente enfoque del Construccionismo concilia con el fenomenólogo francés. $2^{\circ}$ ) La inexorable implicación de la memoria, confirmando un sujeto lleno de recuerdos que registra (también visualmente) con lecturas e imágenes vivientes (Bergson, 2001: 183). Y $3^{\circ}$ ) La indagación escrutadora, o incluso azarosa, que el nuevo espacio-objetual demanda y exige; ya que el anterior orden escenográfico ha sido suplantado por este juego que, a modo de acertijo incompleto, ya hubimos definido 'de lo insólito". Aquí es notable la aportación del concepto de "vistazo" -o "glance"- donde el estudiante, o cualquier observador activo, coparticipa haciendo un esfuerzo por comprender/descifrar (Bryson, 1991). La insuficiencia de la imagen-objeto (en tanto obliga a buscar elementos implícitos o ausentes que la exceden), la sospecha ante tales incógnitas, y la incertidumbre en que cosechar nuestro argumento, son características que se desprenden del vistazo o mirada brysoniana.

De ahí que invistamos el nuevo territorio hermenéutico (y ético) de la responsabilidad. Una mirada responsable es aquélla que se sabe concernida, y a la que compete construir el sentido y el discurso de lo que ya no se aparece explícito y completo. Si rompemos la viciada lógica de la imagen instructora, de lo obvio o evidente, estrenamos el territorio al que venimos situando al alumnado de nivel universitario en Educación Artística. 


\section{La Transestética y su convergencia en Educación Artística: lo relacional y la interacción colectiva}

Cuando Baudrillard acuñó en 1990 el término Transestética, lo hizo para denunciar una cultura invasora que prolifera con nuevos dictados, discursivos o subliminales, aunque ya no sean los del ojo y el verbo únicamente. Lo que nos incapacita para -además de jugar- poder inventar y decidir aquellas reglas de nuestros juegos. Esto lo resume muy bien cuando afirma que "detrás de todo el movimiento convulsivo del arte contemporáneo existe una especie de inercia, algo que ya no consigue superarse y que gira sobre sí en una recurrencia cada vez más rápida" (Baudrillard, 2001: 21). Una cultura, en suma, imperativa y vigilante que empleando la celeridad (nada más volátil que el universo informativo y visual de Internet) bloquea o constriñe un proceso creativo decidido voluntario y crítico-. Lo que deja un babel de producciones artísticas iteradas que abundan, intoxican y desencantan; principal problema de la Postmodernidad, al que varios autores han dedicado su atención, y al que los docentes de Artes Visuales no quedamos nada ajenos (en tanto nuestro alumnado es, también, una muestra de la intoxicada y desencantada sociedad).

Esto ha abierto otro problema que, no desarrollaremos en este espacio, pero tampoco puede soslayarse: el de la especulación y mercantilización del arte en un clima de inercias dictadas. Lyotard ya lo advirtió, con clara lucidez, en una conferencia en Berlín en 1983: cuando lo artístico asimila su éxito a lo comercial, emprende estrategias semejante a como haría un publicista, y las hace pasar por innovación o creación; "se retornan fórmulas confirmadas por éxitos precedentes, se las desequilibra por medio de combinaciones con otras fórmulas en principio incompatibles y de amalgamas de citas, ornamentaciones, pastiches [...] De tal modo, se cree expresar el espíritu del tiempo, cuando no se hace sino reflejar el del mercado" (Lyotard, 1998: 110).

En este deslizante panorama, entre la inercia cultural y el descarado mercado (con su camuflada mercancía artística), la gente ambula con doble sospecha: como público o espectadora, y como creadora -estresada por la condición de autoría y por valores detentados-. ¿Quiénes deciden y retienen tales valores? ¿y cómo despertar, el criterio, ante el fenómeno de la masificación informativa visual, que ya parece más estratégico que espontáneo o inocente? Volvamos a los surrealistas, como defendimos en anterior contribución, a fin de ignorar 'intoxicaciones presentes' y dar oxígeno a la posibilidad de hacer, de crear, también investigando y comentando; recuperando lo que no asumiremos como utopía ni ingenuidad. Recuperando una libertad creativa que se sabe en interacción constante con el mundo, sin que por ello deshabilite el ethos y la mirada introspectivos y comprometidos. Esta fórmula propositiva, "volvamos", también nos lleva al sujeto nietzscheano que conoce las opciones: entre asumir valores ajenos impuestos (es decir asumirlos acríticamente, por la inercia que denuncia Baudrillard), y tomar conciencia de engendrarlos (usando, eso sí, las herramientas y los estímulos que rodean nuestro cuerpo fenoménico). La afirmación propia no precisa liquidar el material dado de la vida; sino jugar 
con él, a partir de él, para hacerse preguntas y respondérselas mientras investigamoscreamos-aprendemos. Algo en que el método a/r/tográfico demuestra que bien puede guiar el proceso.

Del confuso panorama aquí dibujado, el concepto transestético promete obtener un marco epistemológico y heurístico óptimo: como dijimos, la literatura especializada habla de "indagar", "descubrir", poniendo énfasis en una "indagación vital" que sea capaz de relacionar críticamente los textos, las imágenes y los contextos (Irwin, Golparian y Barney, 2017: 135). Esto que ha venido en bautizarse "arte relacional": aquél que toma por horizonte las interacciones humanas en su contexto social y "se inspira sobre todo en los procesos flexibles que rigen la vida en común" (Bourriaud, 2008: 56). Y a lo que antes se hubo llamado 'obra' (hecha, acabada, muerta), ahora se le llama "una duración por experimentar, como una apertura posible" (ibidem, p. 14). Esto mismo, o muy próximo, que ya ha sido advertido desde las "implicaciones extraartísticas" del arte (Jiménez, 2010: 165); y que ha suscitado la necesidad de postular un "arte crítico" que anime a tomar conciencia de los dictados dominantes, más o menos velados, pero ahondando en la propia confianza que se logra con una mirada comprometida e introspectiva: porque "los explotados rara vez han necesitado que se les expliquen las leyes de la explotación. Porque no es la incomprensión [...] lo que alimenta la sumisión de los dominados, sino la falta de confianza en su capacidad para transformarlo" (Rancière, 2012: 59).

En una reciente aportación se ha puesto el énfasis en el beneficio educativo de un marco transestético (Luna, 2019), comprendiéndose que cada práctica artística se incardina en un juego vital donde, los contextos y poderes de entonces, no deben omitirse; y alertos de que la sola palabra arte será continuamente asaltada por estrategas y mercados que la conviertan en su idea, emblema, truco o fetiche para propagarse y colonizar espacios intelectuales (Santamaría, 2016). Enseñar desde este paradigma, ayuda a desbloquear el hoy más frecuente óbice a la creatividad: el de índole cultural (estereotipos y valores que socializan al individuo hasta atosigarlo o detenerlo).

Así, volver al rol híbrido que cada uno desempeña en su juego vital, volver a la indagación que los dadaístas y surrealistas abrieron -y los a/r/tógrafos preconizan-, es también volver al democrático patrimonio creativo de Dewey, con la mirada cargada de memoria (pasado), crítica (presente) y expectativa (futuro).

\section{A propósito de la $\mathrm{A} / \mathrm{r} /$ tografía: el diseño de Proyectos creativos-narrativos con texto-imagen}

Unas previas consideraciones sobre cuándo y cómo empiezan los artistas a reivindicar su fuero creativo (cuyas amenazas consumadas hemos tratado antes), nos llevan al umbral del siglo de las vanguardias. Citemos como ejemplos a Paul Signac en 1891: "El pintor anarquista no es aquél que representa cuadros anarquistas, sino quien sin preocupaciones de lucro, sin deseo de recompensa, lucha con toda su individualidad contra las convenciones" (González, Calvo y Marchán, 2009: 36); a Ósip Brik en 1918: "Es preciso que todos los artistas se liberen al punto de toda somnolencia ideológica, agucen 
la vista y se apliquen a una actividad realmente creativa. Fábricas, talleres y laboratorios esperan la llegada de los artistas, que han de ofrecer los modelos, objetos nunca vistos" (ibidem, pp. 175-176); o a Maurice Vlaminck en 1929 con apasionado e intimista alegato: "En el arte, las teorías prestan la misma utilidad que las recetas en medicina: para creer en ellas es preciso estar enfermo. El saber mata el instinto. Uno no hace pintura, hace su pintura. Me esfuerzo por volver a los instintos que dormitan en lo profundo del subconsciente, de lo que fuimos despojados por la vida superficial, por las convenciones" (ibidem, p. 52).

Semejantes testimonios -éstos son sólo algunos-, recogidos en fechas de cultivo y cocción del Dadá, el Surrealismo y las otras Vanguardias, parecen tener en común combatir las "convenciones" y anticipar lo que después va a suceder (y que posteriores ensayos ya citados van a abordar). $Y$ cuando entonces se temía que, las nuevas propuestas mismas, también podían caer en fraguar una "convención" con sus reglas, y funcionar como laboratorios de ideas formales, se revolucionaba el motor un salto más: indefiniendo al arte como "la realidad de un mundo transpuesto según nuevas condiciones y posibilidades [...] que pertenece en sus innumerables variaciones al espectador" (Tzara, [1918] 1999: 10). El hito es que se despertó una amplia conciencia por vindicar al colonizado arte. Defensas que no se explican sin amenazas y opresiones reales. Incluso cuando el Surrealismo ya había consolidado sus dos primeros Manifiestos de los tres, Breton se vio obligado en una conferencia en Bruselas en 1934 a pronunciar estas palabras:

"La reivindicación surrealista se expresa [con] una intransigencia perfectamente libre por cuanto no reconoce ningún límite exterior a ella [...] El concepto de surrealidad, que tanto han querido echarnos en cara, que tanto han querido convertir en cuerda metafísica o mística con la que ahorcarnos, no se presta ya a equívoco alguno y demuestra no ser en nada contraria a esa necesidad de transformar el mundo que, siempre con más acierto, acometemos" (Breton, 2017: 31).

En común a todas estas expresiones y alegatos, que no sólo testimonian un momento sino una problemática que no entiende de épocas, se encuentra la aspiración connatural del querer decir, hacer, mirar, y comentar las cosas, sin los dictados políticoculturales de turno a que se refiere Baudrillard.

Trasladamos este pulso latente a la enseñanza artística, y precisamos entonces de una metodología integral que capacite y permita, al estudiante, mirar (indagar, investigar), hacer-decir (crear, narrar) y comentar (analizar, reflexionar): acciones, o facetas de un mismo proceso, reunidas precisamente en la A/r/tografía.

Cuando las metodologías simplemente cuantitativas o cualitativas ya habían demostrado su insuficiencia en Artes Visuales, Eisner emprendió la senda híbrida de un método con entidad propia por primera vez; contradiciendo así a otros colegas norteamericanos como el propio Howard Gardner (cuyo escepticismo radicaba en no ver el arte, per se, material y método de investigación; sino únicamente posible objeto de investigación al que otros métodos verbocentristas, o alfanuméricos, debían auxiliar). Una vez se ha superado la espuria dicotomía entre valores expresivos y cognitivos -lo que 
recientemente se ha abogado como "cognición expresiva" (Caeiro y Muñiz, 2019)-, las prácticas artísticas se han legitimado y probado para indagar situaciones personales y problemas sociales, recurriendo a "elementos y estrategias que son mucho más evocativas que denotativas [por su] fuerte capacidad de empatía [y que] aumentan la pluralidad y diversidad de preguntas e interrogantes que podemos hacernos sobre las situaciones" (Roldán y Marín, 2012: 27-28).

De hecho, Marín Viadel asume que "el territorio de las artes suele comenzar cuando las palabras, las imágenes visuales o las sonoras [...] o la combinación de varios o de todos ellos abandonan o trastocan la seguridad de lo convencional" (ibidem, p. 28). Y dado que nosotros proponemos, desde un principio, situándonos en un paradigma integral, relacional, y holístico, resulta claro que aquellos monolenguajes basados en datos y discursos lógicos han de suplantarse por metalenguajes: en que, la metáfora, juega un valor elemental (ya no sólo una finalidad retórica). Y, sobre aquel primero, emplear los espectros del lenguaje estético o poético. Este giro filosófico y metodológico, en que al valor denotativo se le han reconocido sus límites, es bien explicado en el nuevo contexto:

"La Investigación Visual Basada en las Artes nos recuerda que los datos no 'se encuentran', sino que 'son construidos'. Esto refuerza la autoridad tanto del investigador como del lector para crear significados personales" (Cahnmann-Taylor y Siegesmun, 2008: 101).

Cuando la A/r/tografía (acrónimo de art, research y teaching) nace en 2004 de la mano de Rita Irwin y Alex De Cosson, evoluciona en un desarrollo integral con tales bases, alcanzando "un proyecto intelectual integrado" (Roldán y Marín, 2012: 30) que no estandariza un método sino, más bien, se comporta rizomático. La propia investigadora y profesora de la Universidad de Columbia Británica (Canadá) nos reconoce, a los actores implicados en nuestra Área, "habitantes de esa zona fronteriza en la medida en la que recrean, investigan y reaprenden modos de conocimiento, apreciación y representación del mundo" (Irwin y De Cosson, 2004: 29). En esta tesitura ya hemos sostenido que, como trasladamos al alumnado, texto e imagen son códigos o lenguajes expresivo-cognitivos de igual nivel de importancia. Y manejamos ejemplos concretos del Dadá o Surrealismo para hacer entender que, las imágenes no auxilian ni describen los textos (caso de ilustraciones subsumidas a éstos), ni los textos funcionan tampoco de ese modo. El prejuicio de la interdependencia entre ambos se sustituye por una experiencia simbionte, en que imagen y texto conservan entidad propia y se alimentan. En esta línea han contribuido autores fundacionales de la A/r/tografía, implicando la fotografía y la poesía escrita (Leggo e Irwin, 2018); y otros casos que en España han logrado éxito y difusión. A propósito de un proyecto liderado en Granada por la maestra Bustamante Díaz -"Las imágenes y las palabras"-, Joaquín Roldán asevera que "el propósito es demostrar visualmente que las imágenes y los textos escritos nunca pueden solaparse completamente" (Roldán y Marín, 2012: 141). Estas concepciones, que en nuestro entorno cercano ya vienen planteadas en Elogio del calígrafo ([1972-1999] 2002) del poeta y teórico del arte José Ángel Valente, han descubierto en la caligrafía china la más antigua prueba de tales postulados. Anne Whiston, investigadora del MIT, lo ejemplifica de este modo: 
DOI: https://dx.doi.org/10.17561/rtc.19.5487 Investigación
La cuestión imaginativa: del dibujo y la fotografía a la imagen en movimento Enero 2021

"Un haiku es una imagen condensada [...] La fotografía es a ver lo que la poesía es a escribir: una forma concentrada de pensar, una narración condensada [...] Las palabras, también, son imágenes, que revelan lo que he podido ver o entender. La poética es más que la estética; implica significado y, por lo tanto, lenguaje" (Whiston, 2017: 90-91).

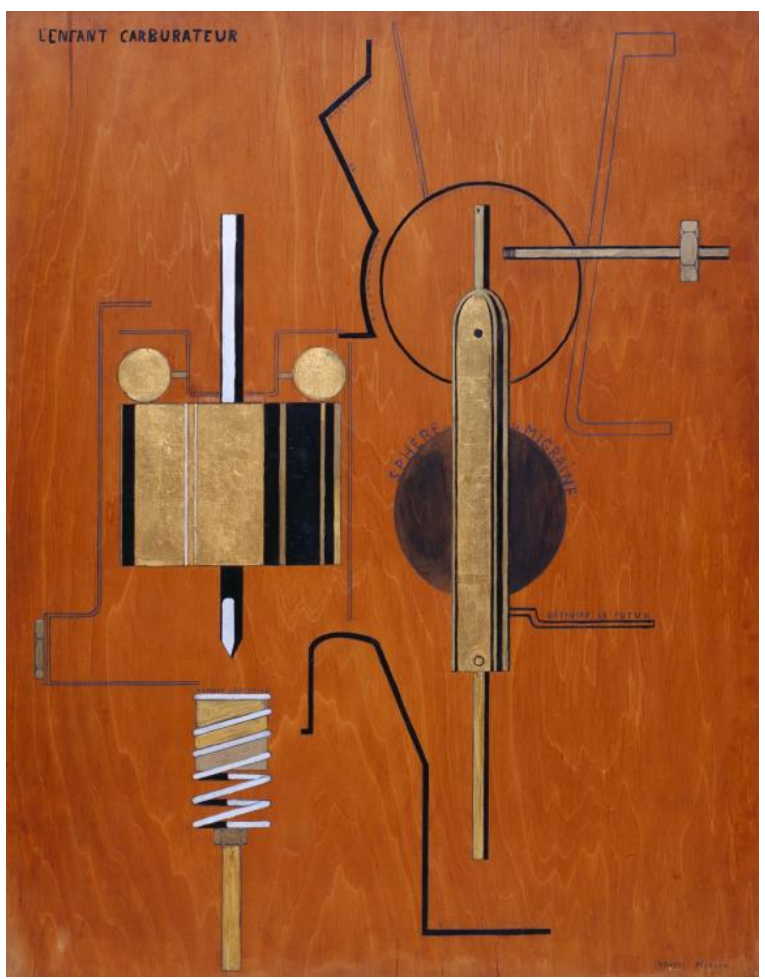

Ilustración 1: Carburador infantil / Óleo, esmalte, laca, pan de oro, grafito y cera, 1919 / Francis Picabia / Fuente: Web

Entre alguno de los ejemplos manejados en el aula, queremos destacar el de la pieza "Carburador infantil" (1919) de Francis Picabia. Esta producción dadaísta hecha con óleo, esmalte, laca, pan de oro, grafito y cera, presenta sugerentes inscripciones textuales en francés que conforman -no anotan- la obra gráfica: tales como "flujo y reflujo de las resoluciones"; "disolver la prolongación"; "la esfera de la migraña"; "destruir el futuro"; y "método cocodrilo". Una obra gráfica (icónico-textual) donde no se emplean lenguajes clásicamente lógicos y narrativos, ni se obedece a valores denotativos como dijimos. Su más aceptada interpretación la ha dado Jan Avgikos (de la Universidad de Lesley y Escuela de Artes Visuales de Nueva York): situándola como un hábil relato acerca de lo impotente, o inoperativo, de aquellos elementos mecánicos que engranan la 'máquina' o el 'combustible' del amor no consumado; figurando, en su composición, la analogía sexual 
DOI: https://dx.doi.org/10.17561/rtc.19.5487 Investigación
La cuestión imaginativa: del dibujo y la fotografía a la imagen en movimento Enero 2021

con los genitales femenino y masculino. Este lenguaje maquinal (que tres años después Picabia repite en su acuarela y tinta "Máquina de sumar") se ha leído como metáfora del efímero y fortuito placer sexual que desencadena la procreación humana, según William Camfield (de la Universidad de Rice). Una maquinaria inmadura que puede guardar conexiones con la cópula y el engañoso progreso que la ciencia promete (Avgikos, 2020).

La discusión y reflexión en el aula sobre estos comentarios, paralelo a la indagación visual de la pieza y a la documentación de poemas escritos por el mismo Picabia (Pellegrini, 2012: 309-313), ya abren una dimensión del método a/r/tográfico (recordemos, no estandarizado sino rizomático). Los cruzamientos de documentos, entendidos como testimonios de un artista, favorecen un clima abierto a averiguar mayores matices en su voz. Porque el medio formal empleado (sea imagen, texto o combinación de ambos) no debe distraernos de investigar las posibilidades de un total producido que, igual, emana pensamiento de una misma experiencia vital.

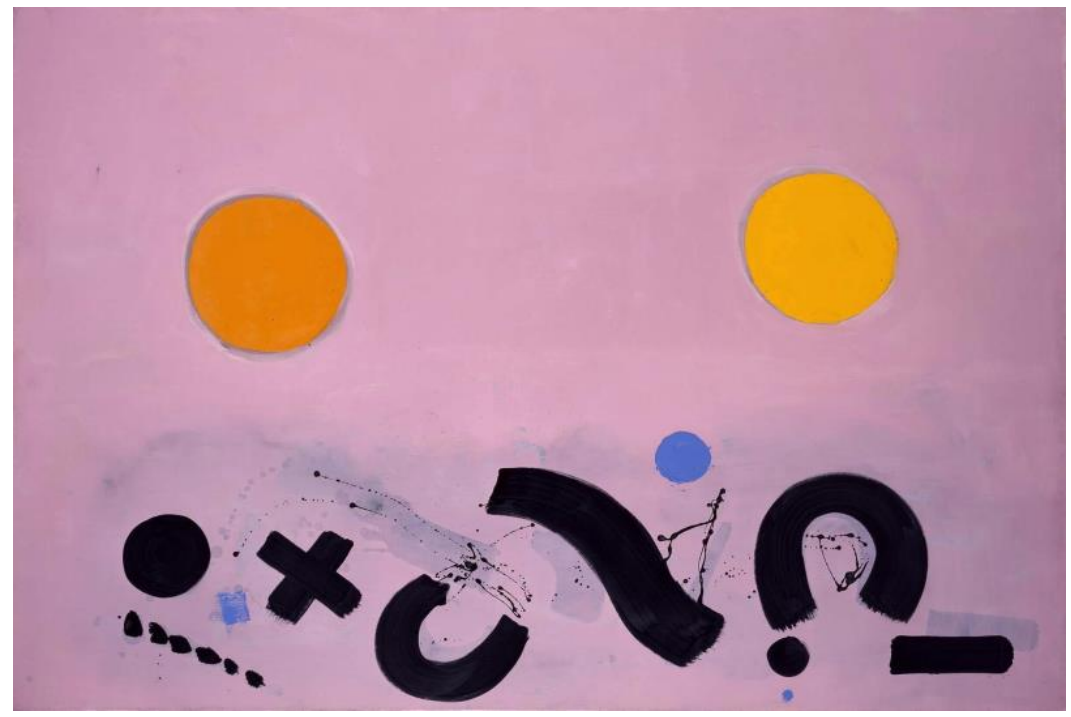

Ilustración 2: Anotaciones / Óleo, 1966 / Adolph Gottlieb / Fuente: Web

También son referibles otros casos en que, la obra gráfica, evoca o concierne lo icónico y lo escritural, incluso en la fórmula de hacerlos ambiguamente indiscernibles (como Jean-Michel Basquiat en "Calavera" y "Oasis de veneno" [1981], o Adolph Gottlieb en "Anotaciones" [1966] y "Sombras" [1971]). Similar a este último, a propósito de Mark Tobey comenta Valente que, influido por Duchamp y por Teng K'uei, se adentra en los conceptos dadaístas y caligráficos orientales; lo que ya nos documenta una serie de pasos, dados en una vida, indispensables para investigar una producción artística que, no obstante, sigue quedando abierta a nuestra recepción (Valente, 2002). Al principio, hemos señalado el rasgo polifacético del artista de vanguardia como factor que optimiza la 
DOI: https://dx.doi.org/10.17561/rtc.19.5487 Investigación
La cuestión imaginativa: del dibujo y la fotografía a la imagen en movimento Enero 2021

práctica a/r/tográfica; efectivamente comprobamos que ocurre así. Estos cruzamientos testimoniales -pintados, fotografiados, escritos o verbalizados- son por igual registros de una indagación vital. Modelo de visión, más que método, con que animar los Proyectos que entrecruzarán la documentación y la creación propia. Materiales, ajenos y propios, de los que igualmente nos proveemos cuando se trata de andar el camino de la averiguación abierta al hallazgo (y no, estresada por llegar a un objetivo predeterminado).

Es muy frecuente que nuestro alumnado parta de esquemas categoriales donde la crónica vital se reduce a la mera descriptiva de situaciones concretas, sin incorporar elementos vitales del pensamiento abstracto (lo imaginario, lo onírico, lo intuido o conceptualizado filosóficamente, etc.). De ahí que, familiarizarles con el lenguaje estético o poético (que en realidad es una suerte de metalenguajes como hemos visto), sea condición inicial e iniciática -por aquello del decisivo componente experiencial que apareja. Este proceso indagador no se esclaviza a los datos externos o las secuencias lógicas, como ocurre en las otras investigaciones 'tradicionales'. Las Artes Visuales han demandado un tipo de acción que involucra el ritual y el autoconocimiento; de ahí que anteriormente hayamos debido precisar ciertas notas sobre la mirada que, ahora, ha de asumir también el aprendizaje a mirarse. La implicación personal, en este Proyecto intelectual integral, lo hace tan comprometido como nos inviste responsables, decisorios, de narrativas por hacer y por venir.

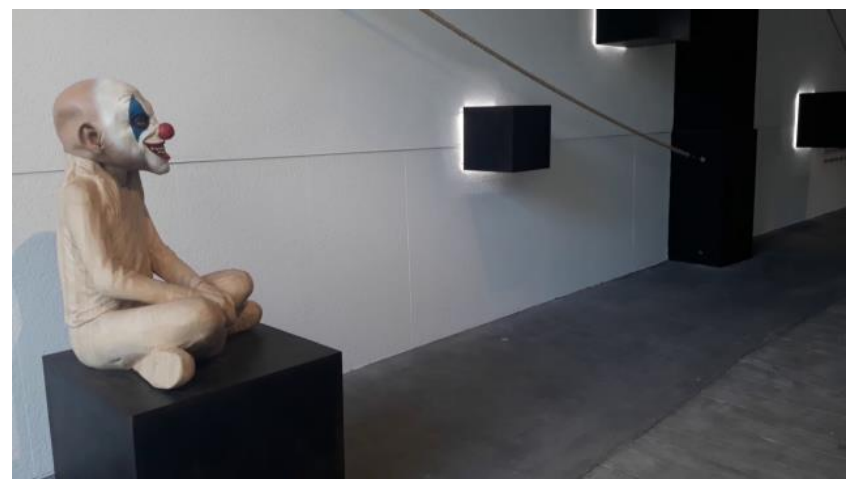

Ilustración 3: Destrucción [Alineación] / Videocreación, 2019 / Estudiantes de la Universidad de León / Fuente: El autor 
DOI: https://dx.doi.org/10.17561/rtc.19.5487 Investigación
La cuestión imaginativa: del dibujo y la fotografía a la imagen en movimento

Enero 2021

Deseamos en este espacio destacar el proyecto indagador y artístico "Destrucción [Alienación]", realizado por un grupo de estudiantes de la Universidad de León, cuyo eje ha sido tomar un objeto crucial (una máscara terrorífica de payaso) para intervenir en espacios públicos haciéndolo interactuar con el entorno. La 'infiltración' de un objeto extraño, inquietante, descontextualiza el espacio de modo que abre la posibilidad de resignificarlo permitiendo que éste pierda su ilación convencional. Lo que ha sido acompañado de un largo proceso en que, lo escritural (mediante automatismo en poemas), y la exploración de imágenes ajenas tomadas de Internet (sobre personas anónimas en lugares remotos), han hilvanado una investigación-acción sobre el juego de la identidad en nuestro ecosistema social. Un ecosistema fuertemente marcado por las biopolíticas que nos afectan. La máscara, el anonimato, la ocultación del disfraz y lo evidente aun pixelado, tejen muy distintas formas-conceptos con que replantearnos una idea tan amplísima como atingente e incluso peligrosa: nuestra identidad.

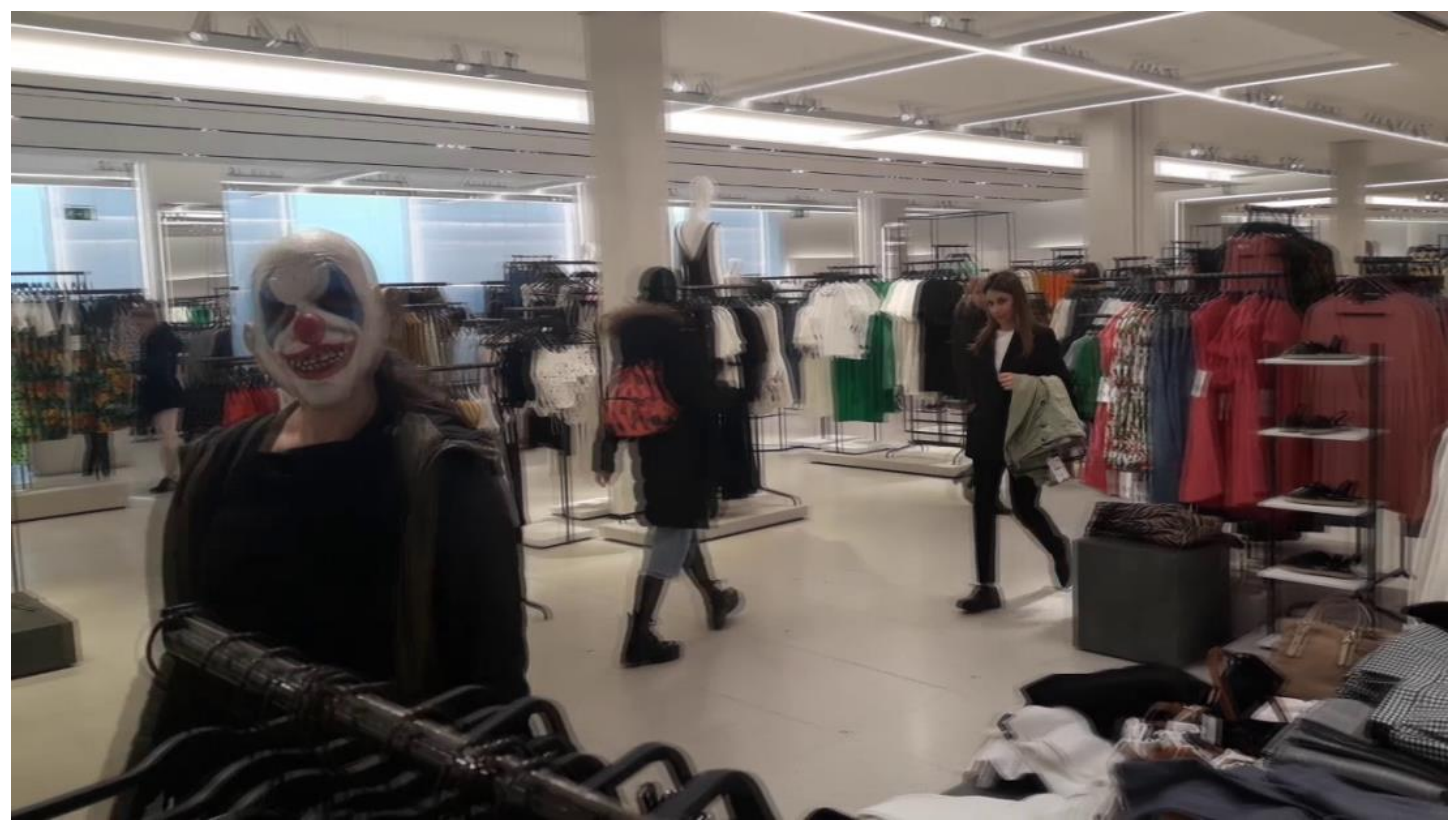

Ilustración 4: Destrucción [Alineación] / Videocreación, 2019 / Estudiantes de la Universidad de León / Fuente: El autor 
DOI: https://dx.doi.org/10.17561/rtc.19.5487 Investigación
La cuestión imaginativa: del dibujo y la fotografía a la imagen en movimento Enero 2021

Así también, por ejemplo, otro proyecto a/r/tográfico realizado, "Forma / Desintegración / Minuto", ha articulado un juego visual entre caligramas (casos pioneros de Apollinaire y Tzara) y paisajes fotografiados de materias dispares cuya forma en cambio no controlamos (nubes, gotas de aceite, etc.). La conjugación de lo forzado, lo intencional, y lo estocástico o irremediablemente efímero en los minutos en que se deshace, ha valido ensayar una reflexión (con citas visuales y literales) acerca de las formas visibles, la intervención humana y el tiempo.

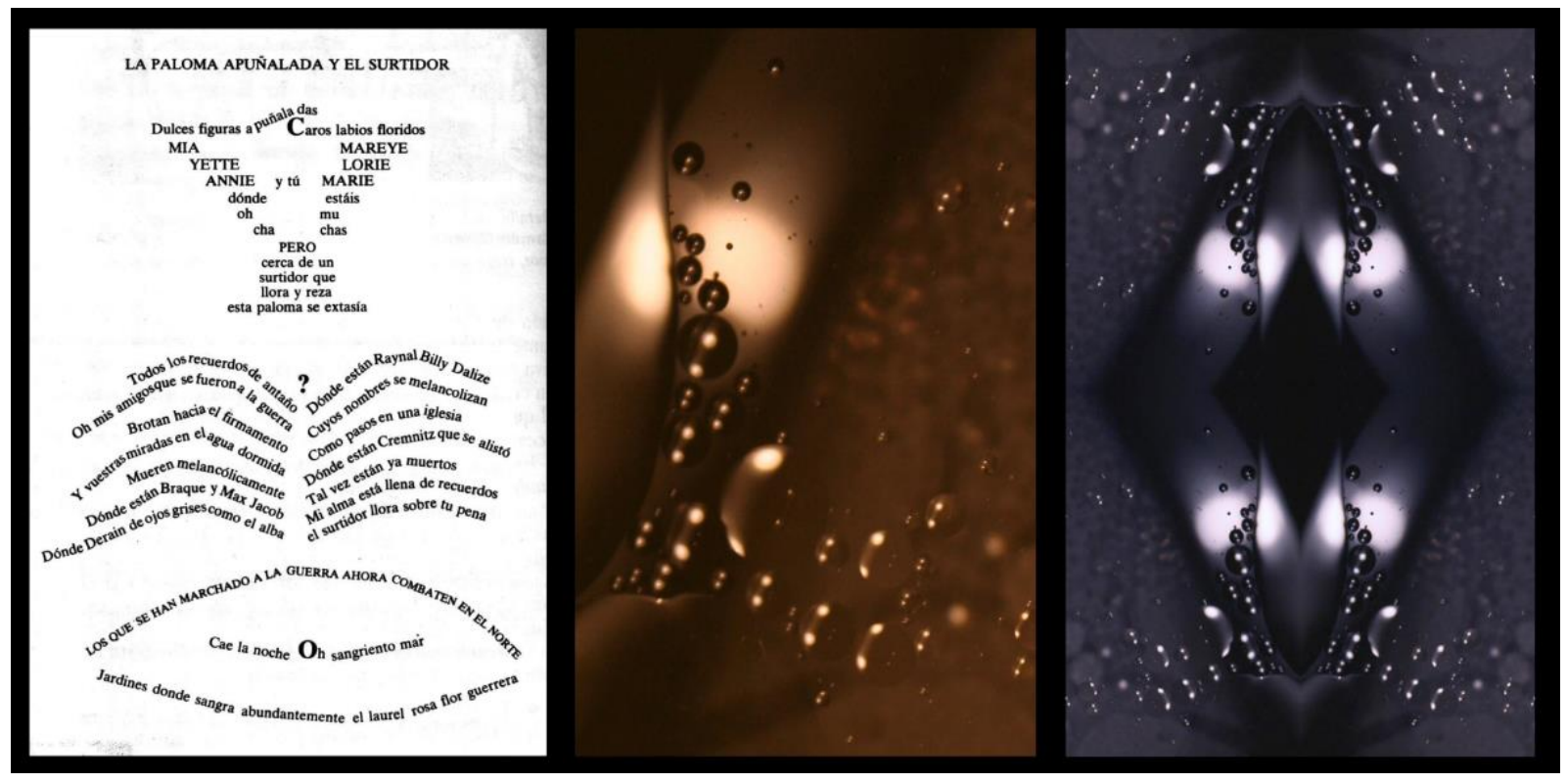

Ilustración 5: Forma/Desintegración/Minuto / Tríptico con hoja de libro escaneada, fotografía digital y fotomontaje, 2019 / Guillaume Apollinaire (poema-caligrama "La paloma apuñalada y el surtidor") y Estudiantes de la Universidad de León / Fuente: El autor

\section{A modo de conclusión: aprendizajes y reflexiones}

De la relación propositiva entre este marco teórico-metodológico y tal modelo de proyectos integrales, se desprende un dispositivo de investigación-creación que facilita el desarrollo de importantes competencias. A saber, las relativas a la capacidad de identificar y comprender ideas propias partiendo de producciones también ajenas. La introspección ha sido una gran omitida en los diseños curriculares. Si pensamos las palabras de Rothko, esto se intuye en aquella nota de los pasados años cincuenta y sesenta sobre la Educación:

"La educación no depende de lo que son realmente las cosas. No consiste sólo en presentar [lo] que el educador estima pertinente que se sepa, sino que 
DOI: https://dx.doi.org/10.17561/rtc.19.5487 Investigación
Artes y Gestión Cultural

ISSN: 2340-9096
La cuestión imaginativa: del dibujo y la fotografía a la imagen en movimento Enero 2021

implica decidir qué categorías, para qué contexto y a qué fin social debe enfocarse tal conocimiento. Todos estos fines son antagónicos con el arte, que reacciona siempre contra la tendencia a ver el mundo compartimentado en categorías y se mueve por la necesidad de recomponer la visión del ser humano completo" (Rothko, 2007: 204).

Empatizamos con esta reflexión porque en ella reconocemos un enfoque, destinado a repetirse reivindicativo, semejante al que ya hemos tocado en este artículo con otros ejemplos. Ese movimiento o reacción, como si fuera orgánico o química, atribuido a la expresión artística, debe ser completado como atribución al amplio campo de la `expresión cognitiva'; del 'conocimiento' humanamente reformulado desde el Construccionismo inclusivo. Sobre las bases del legado de Eisner, el enfoque a/r/tográfico liderado por Irwin ha sido el de mayor idoneidad con este planteamiento. Ahora que contamos con marcos y herramientas adecuados, la tendencia a trabajar en esta dirección no dirigida, o no unidireccional, debe incrementarse. Sostenemos su incremento para así dar testimonios (o, en los clásicos métodos llamados, resultados) de las experiencias que van practicándose. Pues compartirlas con la comunidad de nuestro ámbito -y visibilizarlas ante otras-, es la única forma material de transferencia del conocimiento que puede consolidar una perspectiva aún joven o en crecimiento.

\section{Referencias}

AUMONT, J. (1992). La imagen. Barcelona: Paidós.

AVGIKOS, J. (2020). Francis Picabia. The Child Carburetor. Recuperado de https://www.guggenheim.org/artwork/3409

BAUDRILLARD, J. (2001). La transparencia del mal. Ensayo sobre los fenómenos extremos. Barcelona: Anagrama.

BERGSON, H. (2001). Matière et mémoire. Essai sur la relation du corps a l'esprit. En A. Robinet y H. Gouhier (comp.), Fuvres (6a édition). (pp. 169-223) París: Presses Universitaires de France.

BOURRIAUD, N. (2008). Estética relacional. Buenos Aires: Adriana Hidalgo.

BRETON, André (2017). ¿Qué es el surrealismo? 2a ed. Madrid: Casimiro.

BRYSON, N. (1991). Visión y pintura. La lógica de la mirada. Madrid: Alianza.

CAEIRO, M.; MUÑIZ, M. A. (2019). "La cognición expresiva como experiencia de relación del arte y la ciencia en la educación preuniversitaria". En: Artnodes, 24, pp. 142-154. https://doi.org/10.7238/a.v0i24.3259 
DOI: https://dx.doi.org/10.17561/rtc.19.5487 Investigación
Artes y Gestión Cultural

ISSN: 2340-9096

La cuestión imaginativa: del dibujo y la fotografía a la imagen en movimento

Enero 2021

CAHNMANN-TAYLOR, M.; SIEGESMUND, R. (eds.) (2008). Arts-Based Research in Education. Foundations for Practice. Nueva York: Routledge.

CASTRO, S.; MARCOS, A. (eds.) (2010). Arte y Ciencia: mundos convergentes. Madrid: Plaza y Valdés. https://doi.org/10.5211/9788492751723

DOMÍNGUEZ, J. (2020). "Revisión del Surrealismo para una Educación Artística de lo insólito: del simulacro a la imagen-objeto". En: Tercio Creciente, 17, pp. 33-45. https://doi.org/10.17561/rtc.n17.3

EMMER, M. (2005). "La perfección visible: Matemática y Arte". En: Artnodes, 4, doi: http://dx.doi.org/10.7238/a.v0i4.731

GONZÁLEZ, A.; CALVO, F.; MARCHÁN, S. (2009). Escritos de arte de vanguardia. 3a ed. Madrid: Akal / Istmo, Colecc. Fundamentos.

IRWIN, R.; De COSSON, A. (eds.) (2004). A/R/Tography: Rendering self through Arts-Based Living Inquiry. Vancouver: Pacific Educational.

IRWIN, R.; GOLPARIAN, S.; BARNEY, D. (2017). A/r/tografía como Metodología para la Investigación Visual. En R. Marín y J. Roldán (eds.), Ideas Visuales. Investigación Basada en Artes e investigación artística. (pp. 134-164) Granada: Editorial de la Universidad de Granada.

JIMÉNEZ, J. (2010). Teoría del arte. $1^{a}$ ed., $5^{a}$ imp. Madrid: Tecnos / Alianza, Colecc. Neometrópolis.

KUSPIT, D. (2006). El fin del arte. $1^{a}$ ed., $2^{a}$ imp. Madrid: Akal.

LEGGO, C.; IRWIN, R. (2018). "Ways of attending: Poetry and art". En: Canadian Review of Art Education, 45(1), pp. 50-76. https://doi.org/10.26443/crae.v45i1.48

LUNA, D. (2019). "Desmitificar para educar: hacia una didáctica transestética del arte". En: Communiars, 2, pp. 22-30. https://doi.org/10.12795/Communiars.2019.i02.02

LYOTARD, J.-F. (1998). Lo inhumano. Charlas sobre el tiempo. Buenos Aires: Manantial.

MERLEAU-PONTY, M. (2010). Lo visible y lo invisible. Seguido de: Notas de trabajo. Buenos Aires: Nueva Visión.

PAZ, Octavio (2006). El arco y la lira. $4^{a}$ ed. México: Fondo de Cultura Económica.

PELLEGRINI, A. (ed.) (2012). Antología de la poesía surrealista. 3a ed. Buenos Aires: Argonauta.

PERELLÓ, J. (2005). "Poincaré i Duchamp: Encontre a la quarta dimensió". En: Artnodes, 4, doi: http://dx.doi.org/10.7238/a.v0i4.731

RANCIÈRE, J. (2012). El malestar en la estética. Madrid: Clave Intelectual.

ROLDÁN, J.; MARÍN, R. (eds.) (2012). Metodologías Artísticas de Investigación en Educación. Archidona (Málaga): Aljibe. 
DOI: https://dx.doi.org/10.17561/rtc.19.5487 Investigación
Artes y Gestión Cultural

ISSN: 2340-9096

La cuestión imaginativa: del dibujo y la fotografía a la imagen en movimento

Enero 2021

ROTHKO, M. (2007). Escritos sobre arte. Barcelona: Paidós.

SANTAMARÍA, A. (2016). Arte (es) propaganda. Reflexiones sobre arte e ideología. Madrid: Capitán Swing.

TZARA, T. (1999). Siete manifiestos Dadá. Barcelona: Tusquets.

VALENTE, J. A. (2002). Elogio del calígrafo. Ensayos sobre arte. Barcelona: Galaxia Gutenberg.

WHISTON, A. (2017). El ojo es una puerta. En R. Marín y J. Roldán (eds.), Ideas Visuales. Investigación Basada en Artes e investigación artística. (pp. 120-133) Granada: Editorial de la Universidad de Granada. https://doi.org/10.4995/aniav.2018.9126 